\title{
Radiation Therapy for Grade 3 Gliomas: Correlation of MRI Findings With Prognosis
}

Masashi Mizumoto ${ }^{1}$, Hsiang-Kuang Liang ${ }^{2,3}$, 4 , Yoshiko Oshiro ${ }^{5}$, Masahide Matsuda ${ }^{6}$, Hidehiro Kohzuki ${ }^{6}$, Takashi Iizumi ${ }^{7}$, Haruko Numajiri ${ }^{7}$, Kei Nakai ${ }^{8}$, Toshiyuki Okumura ${ }^{7}$, Eiichi Ishikawa ${ }^{6}$, Hideyuki Sakurai ${ }^{9}$

1. Radiation Oncology, University of Tsukuba Hospital, Tsukuba, JPN 2. Department of Biomedical Engineering, National Taiwan University, Taipei, TWN 3. Division of Radiation Oncology, National Taiwan University Hospital, National Taiwan University College of Medicine, Taipei, TWN 4. Radiation Science and Proton Therapy Center, National Taiwan University College of Medicine, Taipei, TWN 5. Department of Radiation Oncology, Tsukuba Medical Center Hospital, Tsukuba, JPN 6. Neurosurgery, University of Tsukuba Hospital, Tsukuba, JPN 7. Department of Radiation Oncology, Proton Medical Research Center, University of Tsukuba Hospital, Tsukuba, JPN 8. Department of Radiation Oncology, University of Tsukuba Hospital, Tsukuba, JPN 9. Radiation Oncology, Tsukuba University, Tsukuba, JPN

Corresponding author: Masashi Mizumoto, mizumoto@pmrc.tsukuba.ac.jp

\section{Abstract}

\section{Background and objective}

Postoperative radiotherapy is usually indicated for both grade 3 glioma and grade 4 glioblastoma. However, the treatment results and tumor features of grade 3 glioma clearly differ from those of glioblastoma. There is limited information on outcomes and tumor progression for grade 3 glioma. In this study, we evaluate the result of postoperative radiotherapy for grade 3 glioma and focus on the correlation of MRI findings with prognosis.

\section{Methods}

In this study, 99 of 110 patients with grade 3 glioma who received postoperative radiotherapy and were followed up for more than one year were retrospectively analyzed. The total irradiation dose was $60.0 \mathrm{~Gy}$ in 30 fractions, and daily temozolomide or two cycles of nimustine (ACNU) was concurrently administered during radiotherapy. The median follow-up period was 46 months (range: 2-151 months).

Review began 07/09/2021 Review ended 07/27/2021 Published 08/04/2021

(c) Copyright 2021

Mizumoto et al. This is an open access article distributed under the terms of the Creative Commons Attribution License CC-BY 4.0., which permits unrestricted use, distribution, and reproduction in any medium, provided the original author and source are credited.

\section{Results}

In multivariate analysis, pathology [anaplastic oligodendroglioma (AO) vs. anaplastic astrocytoma (AA)], the status of surgical resection (biopsy vs. partial resection or more), and contrast enhancement (enhanced by MRI image or not) were significant factors for overall survival (OS). The five-year OS for AO vs. AA cases were $76.8 \%$ vs. $46.1 \%$, total to partial resection vs. biopsy cases were $72.7 \%$ vs. $21.0 \%$, and non-enhanced vs. enhanced cases were $82.5 \%$ vs. $45.6 \%$, respectively. In multivariate analysis, the status of surgical resection and longer extension of preoperative edema (PE) were significant factors for progression-free survival (PFS). The five-year PFS for the total to partial resection vs. biopsy cases were $52.9 \%$ vs. $10.7 \%$, and non-extensive PE vs. extensive PE (EPE) cases were $62.2 \%$ vs. $19.1 \%$, respectively.

\section{Conclusion}

Our results suggest that a contrast-enhanced tumor on MRI and a longer PE may also be significantly associated with OS and PFS among grade 3 glioma patients.

Categories: Neurology, Radiation Oncology, Radiology

Keywords: glioma, high grade glioma, grade 3, radiotherapy, risk factors

\section{Introduction}

Grade 3 glioma, including anaplastic astrocytoma (AA) and anaplastic oligodendroglioma (AO), is classified as a high-grade glioma. Postoperative radiotherapy is usually indicated for both grade 3 glioma and grade 4 glioblastoma. However, the treatment results and tumor features of grade 3 glioma clearly differ from those of glioblastoma, but there is scarce data on outcomes and tumor progression for grade 3 glioma [1-7].

In imaging, astrocytoma does not show enhancement, and oligodendroglioma shows minimal to moderate patchy multifocal enhancement in up to $50 \%$ of tumors. White et al. have suggested that contrast enhancement is a typical feature of high-grade tumors for AO [1]. Recently, Liang et al. suggested that longer extension of preoperative edema (PE) was significantly correlated with the prognosis of glioblastoma [2]. Grade 3 glioma sometimes also shows long PE, but its significance is unclear. We have conducted three-dimensional conformal radiotherapy (3D-CRT) for grade 3 glioma with concurrent 


\section{Cureus}

chemotherapy postoperatively. In this study, we report the outcomes of grade 3 gliomas treated with radiotherapy, and we focus on identifying factors correlated with the treatment results, including longer PE and enhancement regions.

\section{Materials And Methods}

\section{Patients}

Between 2005 and 2016, 110 patients with grade 3 glioma received postoperative radiotherapy at our center. In this study, 99 of these patients who were followed up for more than one year were retrospectively analyzed (patients who died within one year were included). The patient characteristics are shown in Table 1 .

\begin{tabular}{|c|c|}
\hline Characteristics & Values \\
\hline Age in years, $<60, \geq 60$ & 21-82 (median: 55) 55, 44 \\
\hline \multicolumn{2}{|l|}{ Gender, $\mathrm{n}$} \\
\hline Male & 54 \\
\hline Female & 45 \\
\hline \multicolumn{2}{|l|}{ KPS, n } \\
\hline 100 & 30 \\
\hline 90 & 22 \\
\hline 80 & 20 \\
\hline $40-70$ & 27 \\
\hline \multicolumn{2}{|l|}{ Surgical status, $n$} \\
\hline Gross total resection & 11 \\
\hline Subtotal resection & 24 \\
\hline Partial resection & 39 \\
\hline Biopsy & 25 \\
\hline \multicolumn{2}{|l|}{ Pathology, $\mathrm{n}$} \\
\hline Anaplastic astrocytoma & 56 \\
\hline Anaplastic oligodendroglioma & 43 \\
\hline \multicolumn{2}{|l|}{ Gd-enhanced, n } \\
\hline No & 36 \\
\hline Yes & 63 \\
\hline \multicolumn{2}{|l|}{ PE, $n$} \\
\hline$<2.0 \mathrm{~cm}$ & 53 \\
\hline$\geq 2.0 \mathrm{~cm}$ & 46 \\
\hline
\end{tabular}

\section{TABLE 1: Patient characteristics}

KPS: Karnofsky performance status; PE: preoperative edema

The patients included 54 males and 45 females, and the median age at the start of radiotherapy ranged from 21 to 82 years (median: 55 years). The Karnofsky performance status (KPS) was 40-70, 80, 90, and 100 for 27 , 20,22 , and 30 patients, respectively. The surgical status was biopsy, partial resection, subtotal resection

(STR), and total resection for 25, 39, 24, and 11 patients, respectively; and the pathological results, reviewed by two or more physicians, were AO for 43 patients and AA for 56 patients. On MRI with contrast

enhancement before surgery, tumors were classified into enhanced ( $n=63$ ) and non-enhanced ( $n=36$ ) groups. On MRI before surgery, PE regions were defined as a hyperintense area on T2-weighted or fluid-attenuated 


\section{Cureus}

inversion recovery (FLAIR) MRI or a hypointense area on CT. PE was observed in 72 patients and was absent in 27 patients. The maximum range of $P E$ was $0-9.87 \mathrm{~cm}$ and the mean range was $1.98 \mathrm{~cm}$ in all patients. Extensive PE (EPE) was defined as PE extending at least $2 \mathrm{~cm}$ from the tumor edge. Figures $1-4$ show the supplementary MRI images.
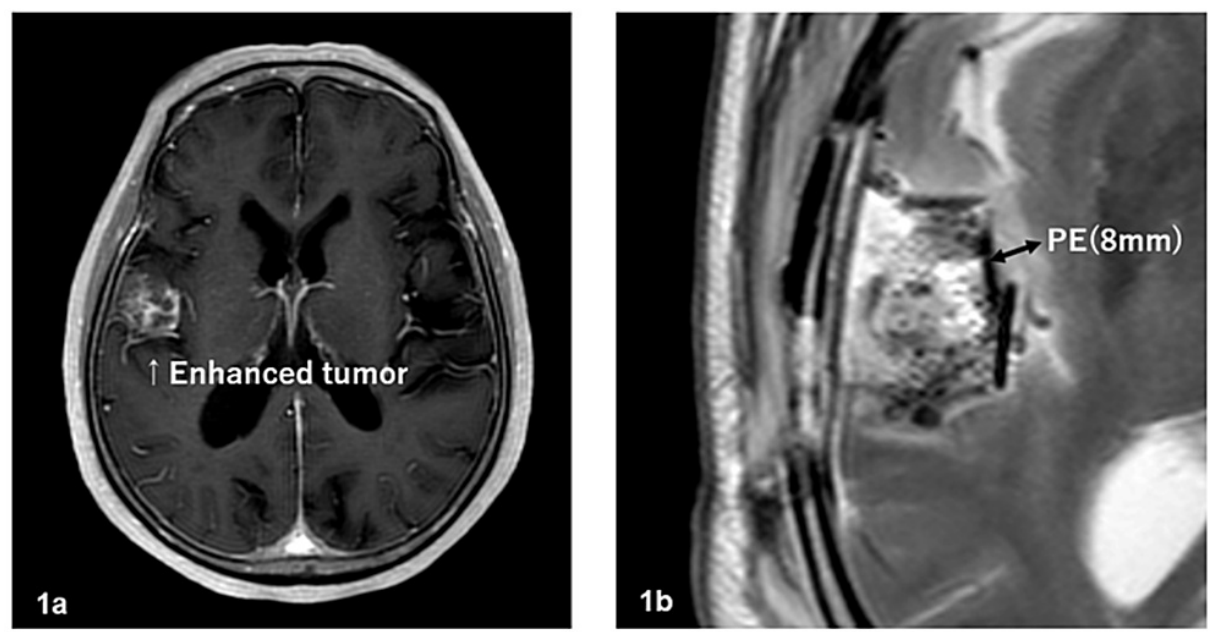

FIGURE 1: Supplementary MRI images - 1

1a: Gd-enhanced tumor before surgery; 1b: 8-mm PE after surgery

MRI: magnetic resonance imaging; PE: preoperative edema
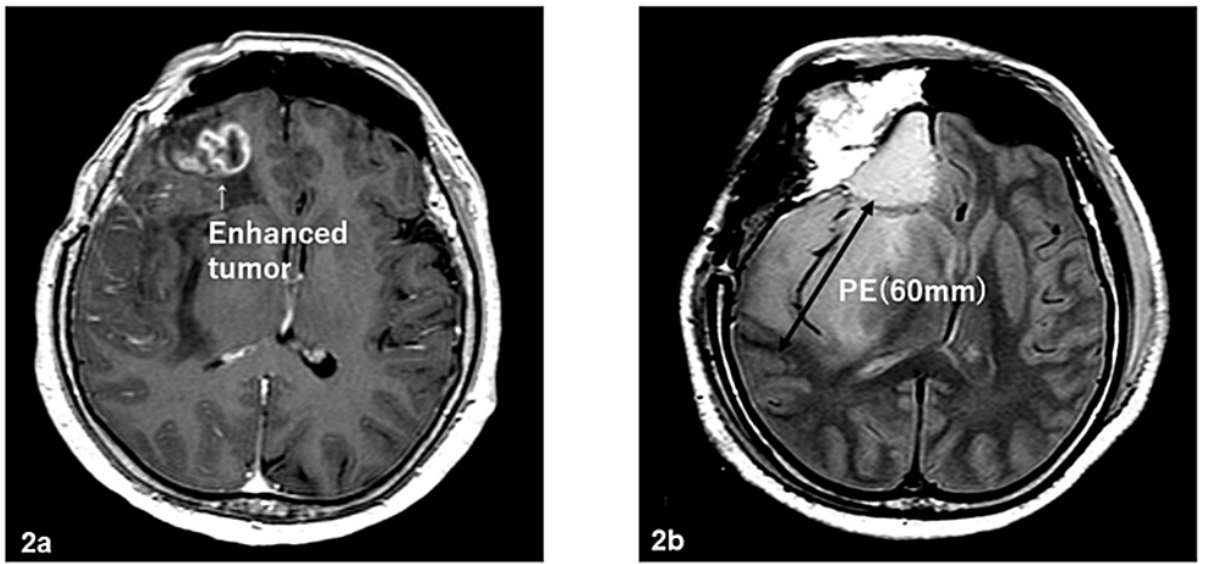

FIGURE 2: Supplementary MRI images - 2

2a: Gd-enhanced tumor before surgery; 2b: 60-mm PE after surgery

MRI: magnetic resonance imaging; PE: preoperative edema 


\section{Cureus}
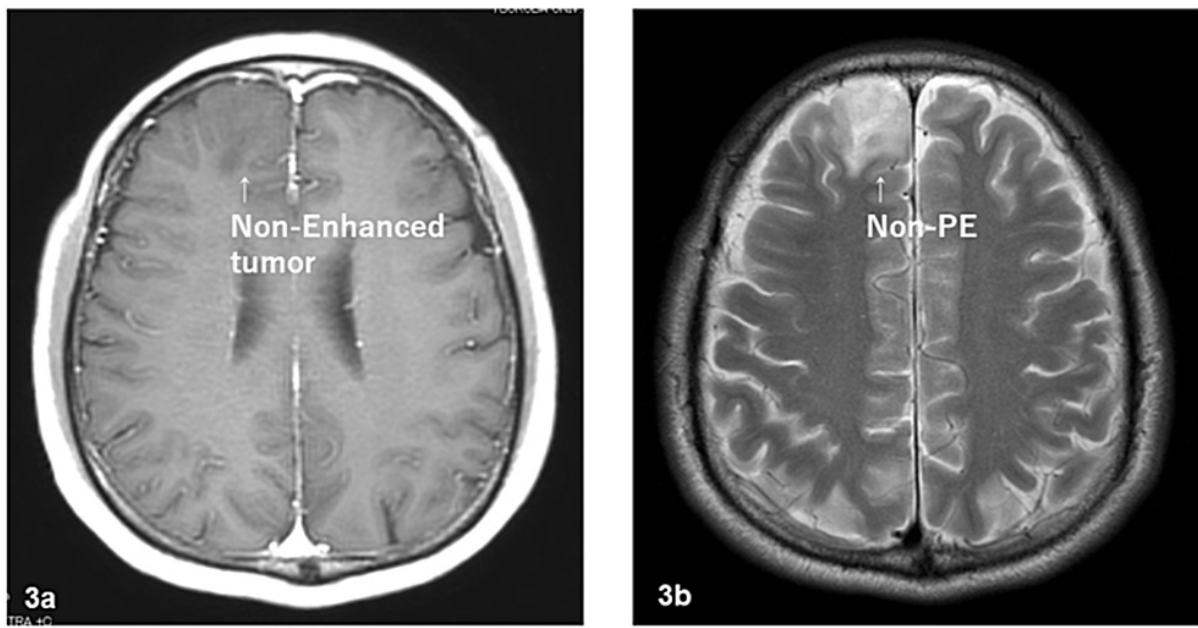

FIGURE 3: Supplementary MRI images - 3

3a: non-enhanced tumor before surgery; $3 b$ : non-PE before surgery. The tumor shapes of $3 a$ and $3 b$ were almost the same

MRI: magnetic resonance imaging; PE: preoperative edema


FIGURE 4: Supplementary MRI images - 4

4a: non-enhanced tumor before surgery; 4b: 5-mm PE after surgery

MRI: magnetic resonance imaging; PE: preoperative edema

\section{Treatment}

All patients received radiotherapy after surgery. Surgical status was classified as gross total resection (GTR), STR, partial resection, and biopsy according to neurosurgeon records. Enhanced MRI was performed within three days after surgery. Treatment planning involved the use of CT images at 3-mm intervals at the treatment position. Based on preoperative MRI, the clinical target volume (CTV)-1 included the entire surgical cavity and surrounding edema plus a $1.2-\mathrm{cm}$ margin. The CTV-2 included the residual tumor or cavity plus a $1.2-\mathrm{cm}$ margin. In the first 23-25 fractions, radiotherapy of $2.0 \mathrm{~Gy}$ per fraction was delivered to CTV-1, and in the last five to seven fractions, the CTV was shrunk to CTV-2. The total irradiation dose was up to $60.0 \mathrm{~Gy}$ in 30 fractions. The planning target volume (PTV) was defined as the CTV plus $3 \mathrm{~mm}$ for setup error. The exposure dose limit was adjusted to $\leqslant 10 \mathrm{~Gy}$ for the lens, $\leqslant 44$ for the retina, $\leqslant 50 \mathrm{~Gy}$ for the chiasm and optic nerve, and $\leqslant 60 \mathrm{~Gy}$ for $1 / 5$ of the brainstem [3,4]. If the dose to an organ at risk exceeded the exposure dose limit, the margin of the lesion was reduced. Chemotherapy with daily temozolomide (75 $\left.\mathrm{mg} / \mathrm{m}^{2}\right)$ for 28 days or two cycles of nimustine (ACNU) $\left(80 \mathrm{mg} / \mathrm{m}^{2}\right)$ was concurrently administered during radiotherapy [3-5]. 


\section{Statistical analysis}

Data analysis and statistical tests were performed using SPSS Statistics version 27 (IBM, Armonk, NY). Overall survival (OS) was calculated from the date of surgery to death. Progression-free survival (PFS) was calculated from the date of surgery to disease progression, including death or tumor progression proven by imaging. Survival was calculated using the Kaplan-Meier method. Differences in survival were compared between the groups by log-rank test. Univariate and Cox regression analyses were performed to evaluate factors that influenced survival, including age ( $<60$ years vs. $\geqslant 60$ years), gender, KPS ( $\leqslant 70$ vs. $\geqslant 80$ ), enhanced region (yes vs. no), status of tumor resection (biopsy vs. partial resection), and PE ( $<2 \mathrm{~cm}$ vs. $\geqslant 2 \mathrm{~cm}$ ). Genetic information was not evaluated because only 26 patients had O6-methylguanine-DNA methyltransferase promoter (MGMT) information and six had 1p/19q codeletion information, respectively.

\section{Ethical approval}

The Ethics and Steering Committees of Tsukuba approved this study and written informed consent was obtained from every patient prior to radiotherapy. The study was conducted in accordance with the Declaration of Helsinki, and the protocol was approved by the Institutional Review Board (Tsukuba Clinical Research \& Development Organization, H30-114).

\section{Results}

The median follow-up period was 46.3 months (range: 2.6-151.9 months). Sixty patients were alive at the last follow-up. The one-, three-, five-, and seven-year OS for all patients was $87.6 \%$ (95\% CI: 81.0-94.1), $69.9 \%$ (60.5-79.3), 59.7\% (49.3-70.0), and 53.9\% (42.6-65.1), respectively, with a mean OS time of 95.3 months (81.8-108.8). The one-, three-, five-, and seven-year PFS for all patients was $71.7 \%$ (62.8-80.6), $50.5 \%$ (40.7-60.3), $42.3 \%$ (32.3-52.2), and 37.8\% (27.6-47.9), respectively, with a mean PFS time of 66.8 months (54.1-79.5). The OS and PFS for all patients are shown in Figure 5.

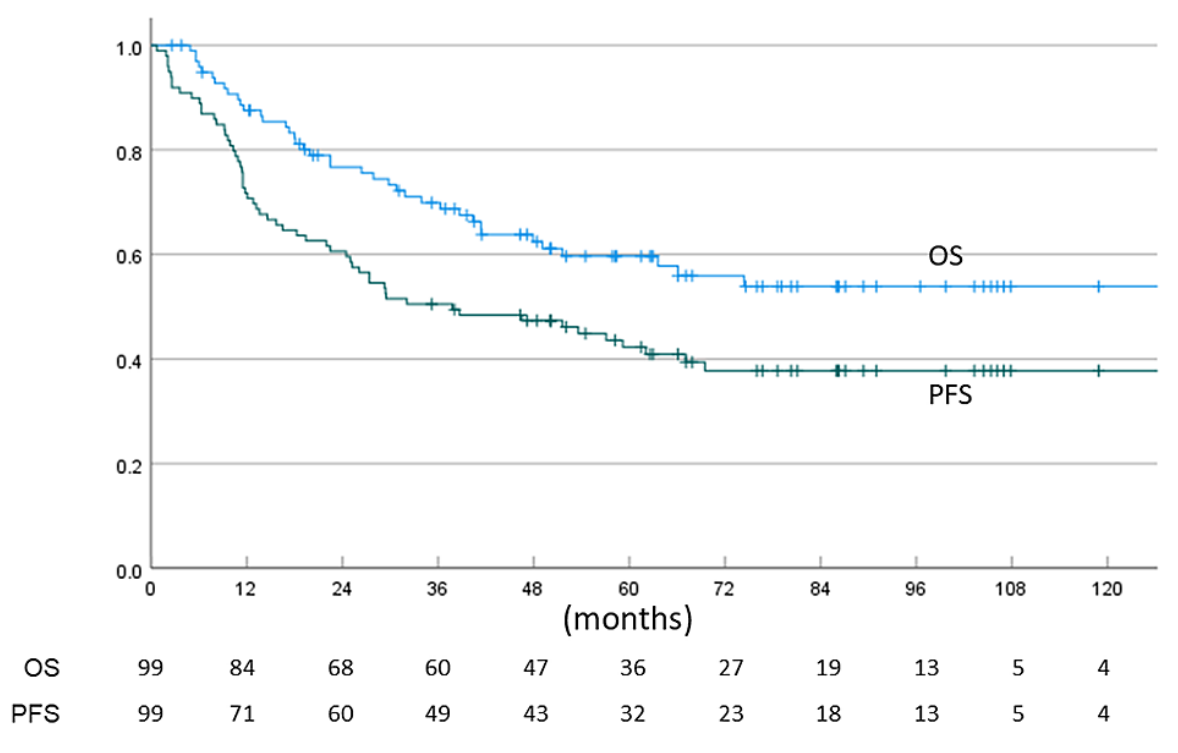

FIGURE 5: The overall survival (OS) and progression-free survival (PFS) for all patients

In univariate analysis, the significant factors for OS were age $(\mathrm{p}=0.031)$, status of surgical resection (biopsy vs. partial resection, STR, and GTR, $p=0.001$ ), pathology (AO vs. AA, $p=0.005$ ), KPS (40-70 vs. 80-100, $\mathrm{p}=0.001)$, enhancement $(\mathrm{p}=0.001)$, and $\mathrm{EPE}(\leqslant 2 \mathrm{~cm}$ vs. $>2 \mathrm{~cm}, \mathrm{p}=0.001)$. In multivariate analysis, pathology $(\mathrm{p}=0.029)$, status of surgical resection $(\mathrm{p}=0.005)$, and contrast enhancement $(\mathrm{p}=0.045)$ were significant factors (Table 2). 


\section{Cureus}

\begin{tabular}{|c|c|c|c|c|c|c|c|c|}
\hline Variable & $\begin{array}{l}\text { No. of } \\
\text { patients }\end{array}$ & $\begin{array}{l}\text { MST } \\
\text { (months) }\end{array}$ & $\begin{array}{l}\text { Three-year survival } \\
\text { (\%) }\end{array}$ & $\begin{array}{l}\text { Five-year survival } \\
\text { (\%) }\end{array}$ & $\begin{array}{l}\text { Standard } \\
\text { error }\end{array}$ & $\begin{array}{l}P \text { - } \\
\text { value }\end{array}$ & $\begin{array}{l}\text { Hazard } \\
\text { ratio }\end{array}$ & $95 \% \mathrm{Cl}$ \\
\hline \multicolumn{9}{|l|}{ Age in years } \\
\hline$<60$ & 55 & - & 75.7 & 69.4 & 0.384 & 0.909 & 0.957 & $\begin{array}{l}0.451- \\
2.031\end{array}$ \\
\hline$>60$ & 44 & 47.9 & 62.1 & 44.6 & & & & \\
\hline \multicolumn{9}{|l|}{ Gender } \\
\hline Male & 54 & 63.6 & 63.7 & 53.1 & 0.365 & 0.248 & 0.656 & $\begin{array}{l}0.320- \\
1.342\end{array}$ \\
\hline Female & 45 & - & 76.9 & 66.7 & & & & \\
\hline \multicolumn{9}{|l|}{ KPS } \\
\hline 70-100 & 52 & - & 83.9 & 74.5 & 0.409 & 0.478 & 1.337 & $\begin{array}{l}0.600- \\
2.980\end{array}$ \\
\hline $40-60$ & 47 & 38.7 & 53.5 & 41.8 & & & & \\
\hline \multicolumn{9}{|l|}{ Pathology } \\
\hline AO & 43 & - & 85.3 & 76.8 & 0.386 & 0.029 & 2.315 & $\begin{array}{l}1.087- \\
4.928\end{array}$ \\
\hline AA & 56 & 41.4 & 57.8 & 46.1 & & & & \\
\hline \multicolumn{9}{|l|}{ Surgery } \\
\hline Total-partial & 74 & - & 81.2 & 72.7 & 0.398 & 0.005 & 3.032 & $\begin{array}{l}1.390- \\
6.615\end{array}$ \\
\hline Biopsy only & 25 & 22.5 & 36.7 & 21 & & & & \\
\hline \multicolumn{9}{|l|}{$\mathrm{PE}, \mathrm{cm}$} \\
\hline $0-1.9$ & 53 & - & 80.6 & 70.2 & 0.386 & 0.435 & 1.352 & $\begin{array}{l}0.634- \\
2.883\end{array}$ \\
\hline$>2$ & 46 & 41.4 & 56.6 & 45.7 & & & & \\
\hline \multicolumn{9}{|c|}{ enhancement } \\
\hline No & 36 & - & 88.6 & 82.5 & 0.462 & 0.045 & 2.53 & $\begin{array}{l}1.022- \\
6.262\end{array}$ \\
\hline Yes & 63 & 49.1 & 58.5 & 45.6 & & & & \\
\hline
\end{tabular}

\section{TABLE 2: Multivariate analysis of potential predictive factors for overall survival}

AO: anaplastic oligodendroglioma; AA: anaplastic astrocytoma; KPS: Karnofsky performance status; MST: median survival time; PE: preoperative edema

The one-, three-, five-, and seven-year OS for AO vs. AA cases were $95.3 \%$ vs. $81.5 \%$ (one year), $85.3 \%$ vs. $57.8 \%$ (three years), $76.8 \%$ vs. $46.1 \%$ (five years), and $72.6 \%$ vs. $38.9 \%$ (seven years), with a mean OS time of 119.2 vs. 73.3 months. The one-, three-, five-, and seven-year OS for total to partial resection vs. biopsy cases were $93.0 \%$ vs. $72.0 \%$ (one year), $81.2 \%$ vs. 36.7 (three years), $72.7 \%$ vs. $21.0 \%$ (five years), and $65.4 \%$ vs. $21.0 \%$ (seven years), with a mean OS time of 111.5 vs. 33.0 months. Figure 6 illustrates OS rates for each surgical status. 


\section{Cureus}

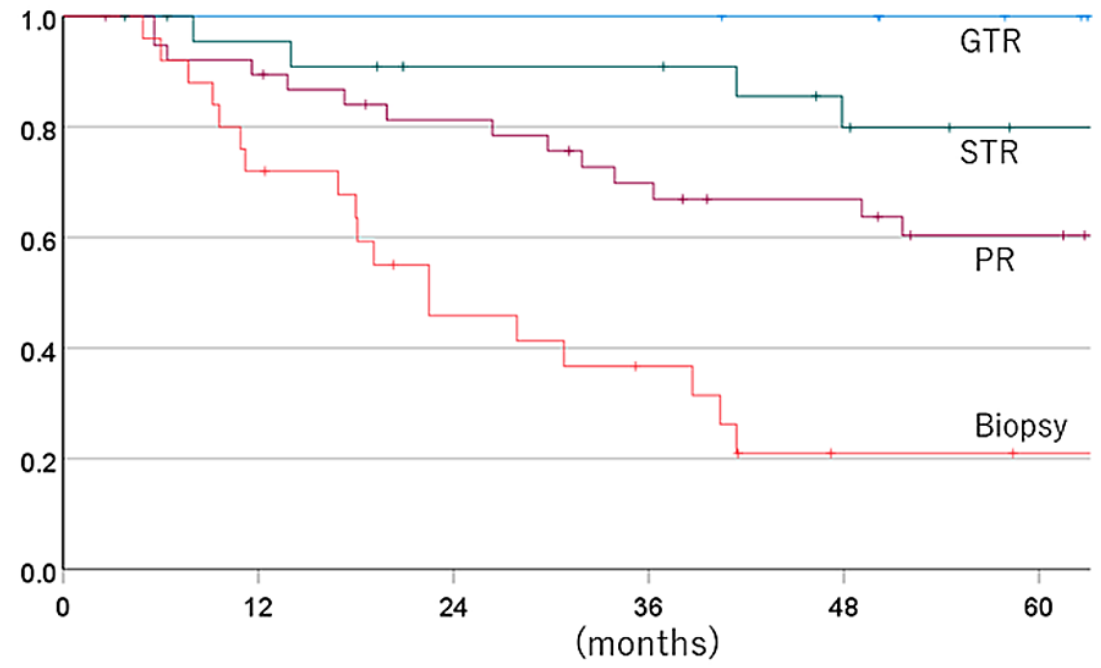

$\begin{array}{rrrrrrr}\text { GTR } & 11 & 11 & 11 & 11 & 10 & 7 \\ \text { STR } & 24 & 21 & 18 & 18 & 14 & 11 \\ \text { PR } & 39 & 34 & 29 & 24 & 21 & 17 \\ \text { BP } & 25 & 18 & 10 & 7 & 2 & 1\end{array}$

\section{FIGURE 6: Overall survival rate for each surgical status}

GTR: gross total resection; STR: subtotal resection; PR: partial resection; BP: biopsy

The one-, three-, five-, and seven-year OS for non-enhanced vs. enhanced cases were $100 \%$ vs. $80.1 \%$ (one year), $88.6 \%$ vs. 58.5 (three years), $82.5 \%$ vs. $45.6 \%$ (five years), $73.0 \%$ vs. $42.3 \%$ (seven years), with a mean OS time of 123.1 vs. 75.2 months.

In univariate analysis, the significant factors for PFS were age $(\mathrm{p}=0.001)$, status of surgical resection $(p=0.001)$, pathology $(p=0.005)$, KPS $(p=0.001)$, enhancement $(p=0.001)$, and extensive PE $(p=0.001)$. In multivariate analysis, the status of surgical resection and extensive PE were significant factors for PFS (Table 3). 


\section{Cureus}

\begin{tabular}{|c|c|c|c|c|c|c|c|c|}
\hline Variable & $\begin{array}{l}\text { No. of } \\
\text { patients }\end{array}$ & $\begin{array}{l}\text { MST } \\
\text { (months) }\end{array}$ & $\begin{array}{l}\text { Three-year PFS } \\
\text { (\%) }\end{array}$ & $\begin{array}{l}\text { Five-year PFS } \\
\text { (\%) }\end{array}$ & $\begin{array}{l}\text { Standard } \\
\text { error }\end{array}$ & $\begin{array}{l}P- \\
\text { value }\end{array}$ & $\begin{array}{l}\text { Hazard } \\
\text { ratio }\end{array}$ & $95 \% \mathrm{Cl}$ \\
\hline \multicolumn{9}{|l|}{ Age in years } \\
\hline$<60$ & 55 & 128.2 & 65.5 & 57.4 & 0.308 & 0.331 & 1.35 & $\begin{array}{l}0.738- \\
2.470\end{array}$ \\
\hline$>60$ & 44 & 15.7 & 31.8 & 23 & & & & \\
\hline \multicolumn{9}{|l|}{ Gender } \\
\hline Male & 54 & 27.4 & 46.3 & 39.7 & 0.285 & 0.851 & 0.948 & $\begin{array}{l}0.543- \\
1.656\end{array}$ \\
\hline Female & 45 & 57.1 & 55.6 & 45.7 & & & & \\
\hline \multicolumn{9}{|l|}{ KPS } \\
\hline $70-100$ & 52 & 130.1 & 63.5 & 59.1 & 0.329 & 0.813 & 1.081 & $\begin{array}{l}0.567- \\
2.061\end{array}$ \\
\hline $40-60$ & 47 & 16.5 & 36.2 & 24.3 & & & & \\
\hline \multicolumn{9}{|l|}{ Pathology } \\
\hline $\mathrm{AO}$ & 43 & 130.1 & 62.8 & 55.1 & 0.296 & 0.14 & 1.549 & $\begin{array}{l}0.866- \\
2.768\end{array}$ \\
\hline AA & 56 & 25.2 & 41.1 & 32.3 & & & & \\
\hline \multicolumn{9}{|l|}{ Surgery } \\
\hline Total-partial & 74 & 67.1 & 62.2 & 52.9 & 0.339 & 0.01 & 2.392 & $\begin{array}{l}1.231- \\
4.648\end{array}$ \\
\hline Biopsy only & 25 & 11.4 & 16 & 10.7 & & & & \\
\hline \multicolumn{9}{|l|}{ PE } \\
\hline $0-1.9 \mathrm{~cm}$ & 53 & - & 64.2 & 62.2 & 0.335 & 0.043 & 1.973 & $\begin{array}{l}1.023- \\
3.805\end{array}$ \\
\hline$\geq 2.0 \mathrm{~cm}$ & 46 & 15.7 & 34.8 & 19.1 & & & & \\
\hline \multicolumn{9}{|l|}{$\begin{array}{l}\text { Gd } \\
\text { enhancement }\end{array}$} \\
\hline No & 36 & - & 72.2 & 66.6 & 0.372 & 0.289 & 1.483 & $\begin{array}{l}0.715- \\
3.072\end{array}$ \\
\hline Yes & 63 & 16.5 & 38.1 & 28.9 & & & & \\
\hline
\end{tabular}

\section{TABLE 3: Multivariate analysis of potential predictive factors for progression-free survival}

AO: anaplastic oligodendroglioma; AA: anaplastic astrocytoma; KPS: Karnofsky performance status; MST: median survival time; PE: preoperative edema

The one-, three-, five-, and seven-year PFS for the total to partial resection vs. biopsy cases were $79.7 \%$ vs. $48.0 \%$ (one year), $62.2 \%$ vs. 16.0 (three years), $52.9 \%$ vs. $10.7 \%$ (five years), and $47.0 \%$ vs. $10.7 \%$ (seven years), with a mean PFS time of 80.2 vs. 20.5 months. Figure 7 depicts the PFS rate for each surgical status. 


\section{Cureus}

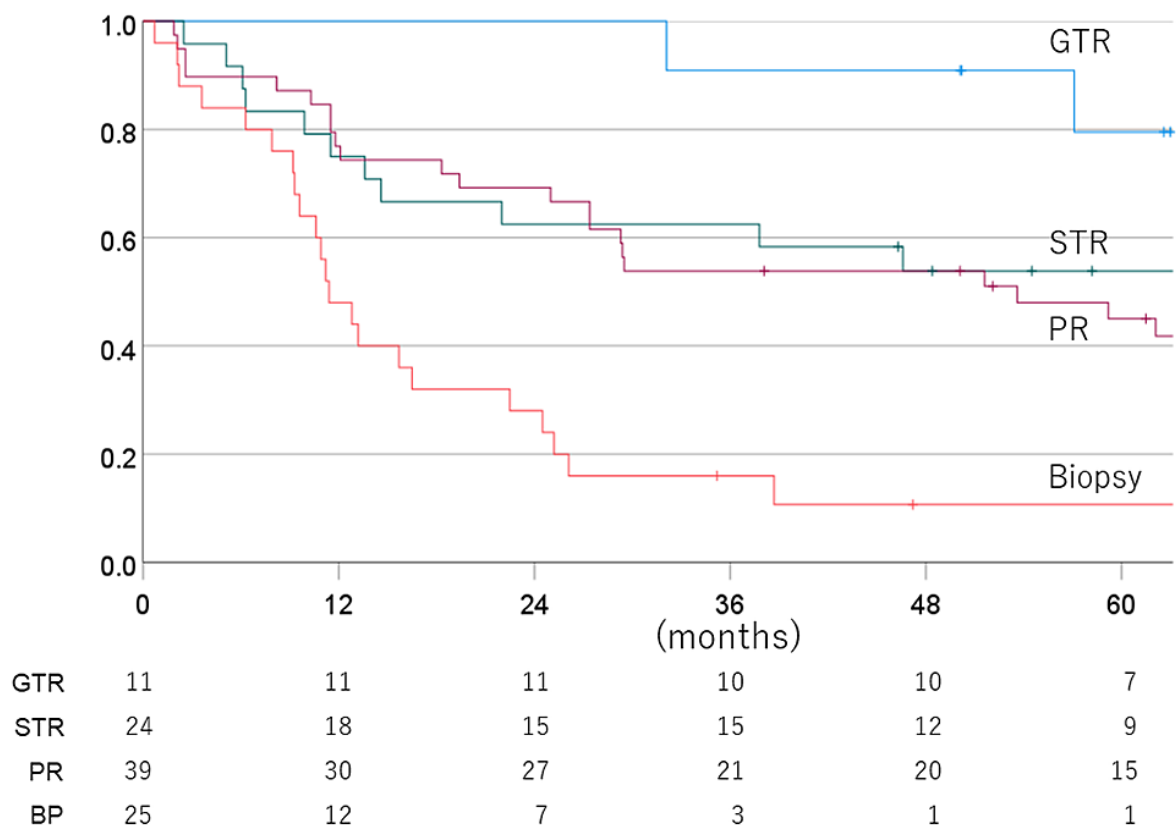

\section{FIGURE 7: Progression-free survival rate for each surgical status}

GTR: gross total resection; STR: subtotal resection; PR: partial resection; BP: biopsy

The one-, three-, five-, and seven-year PFS for non-EPE vs. EPE cases were $81.1 \%$ vs. $60.9 \%$ (one year), $64.2 \%$ vs. 34.8 (three years), $62.2 \%$ vs. $19.1 \%$ (five years), and $56.7 \%$ vs. $15.9 \%$ (seven years), with a mean PFS time of 96.0 vs. 38.2 months. Figures 8 - 11 show the OS rate and PFS rate focusing on MRI image status.

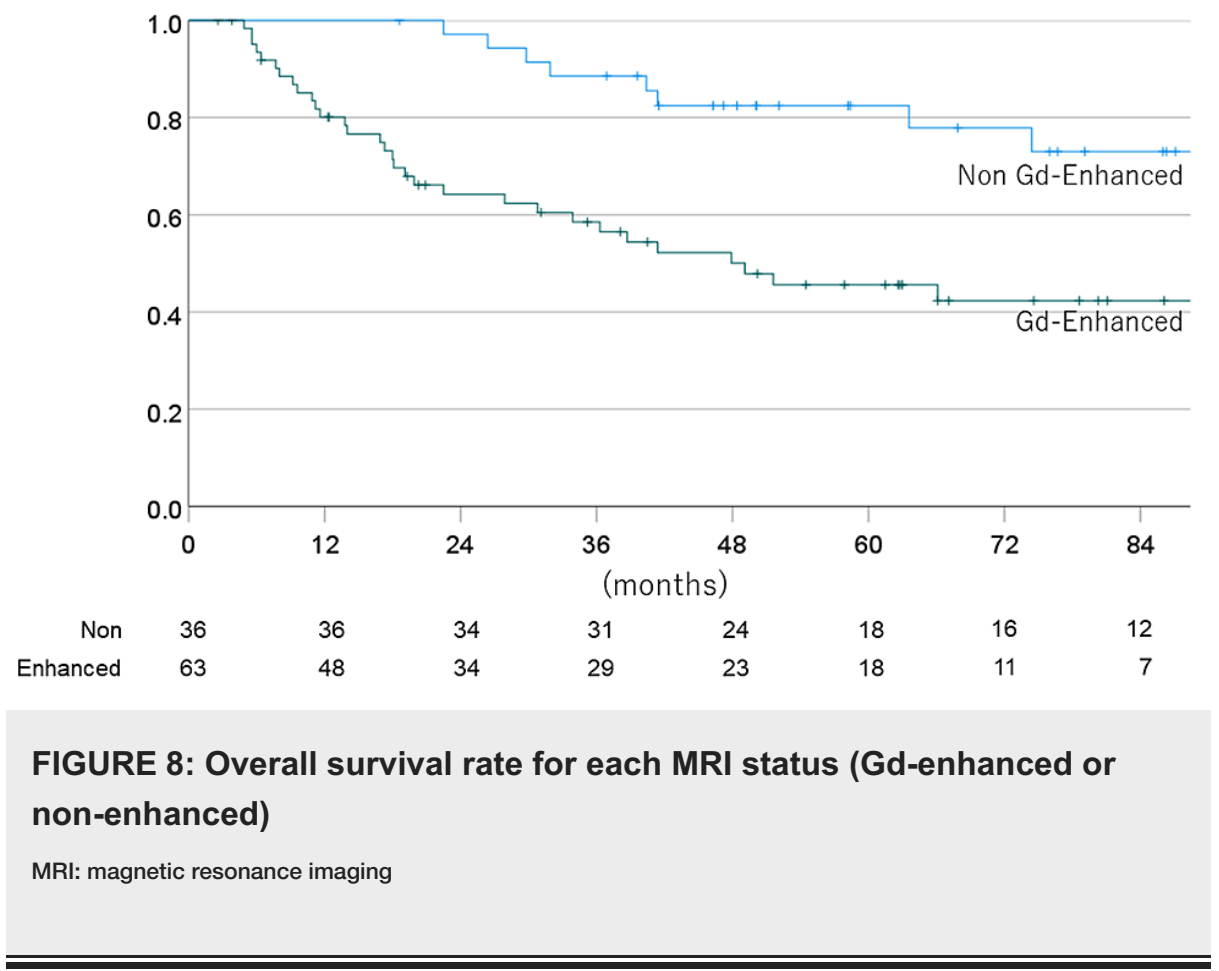




\section{Cureus}

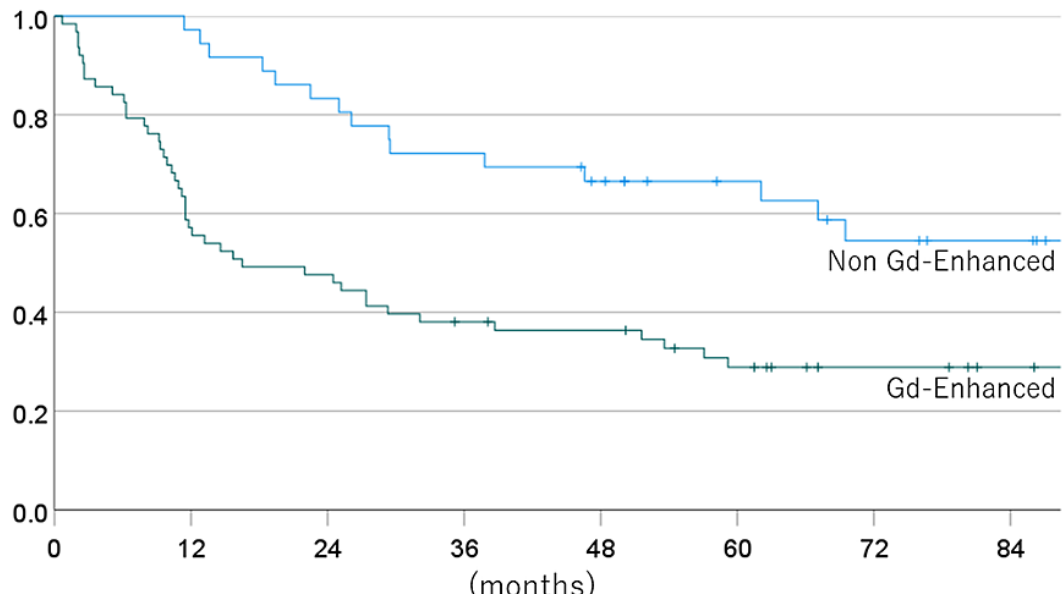

$\begin{array}{rrrrrrrrr}\text { Non } & 36 & 35 & 30 & 26 & 22 & 17 & 13 & 11 \\ \text { Enhanced } & 63 & 36 & 30 & 23 & 21 & 15 & 10 & 7\end{array}$

FIGURE 9: Progression-free survival rate for each MRI status (Gdenhanced or non-enhanced)

MRI: magnetic resonance imaging

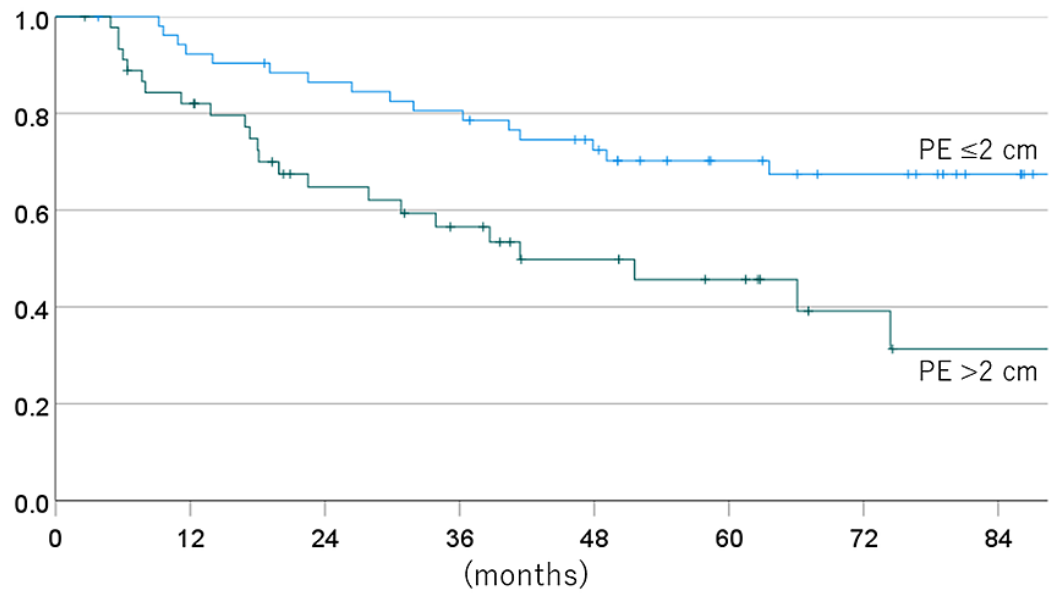

$\begin{array}{lllllllll}\mathrm{PE} \leq 2 \mathrm{~cm} & 53 & 48 & 44 & 41 & 34 & 26 & 22 & 16\end{array}$

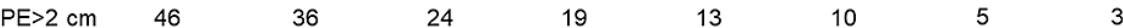

FIGURE 10: Overall survival rate for each MRI status (PE $\leq 2 \mathrm{~cm}$ or $>2$ cm)

MRI: magnetic resonance imaging; PE: preoperative edema 


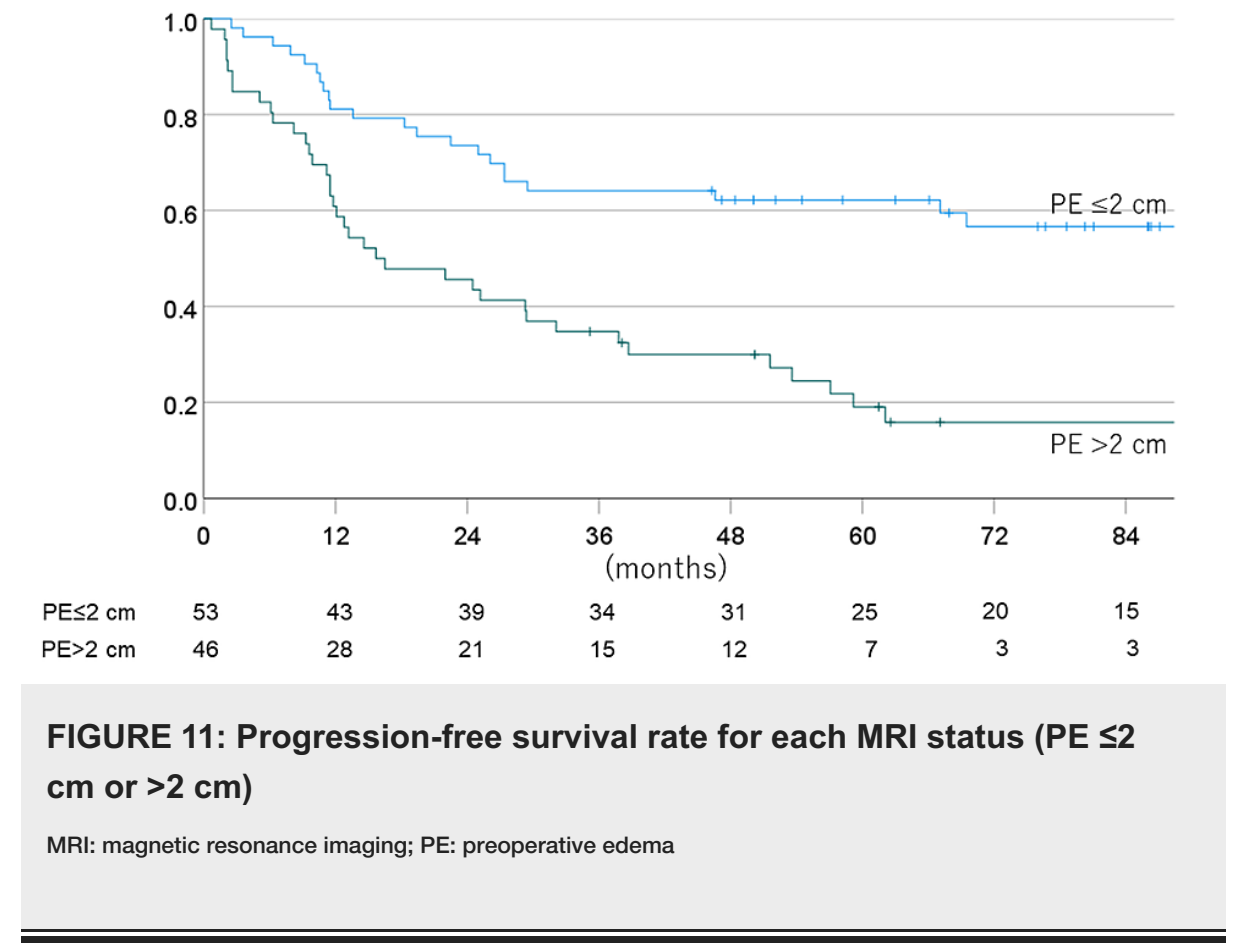

\section{Discussion}

Anaplastic gliomas account for 15-20\% of all malignant gliomas. These tumors used to be included in trials together with glioblastoma as high-grade gliomas, and there have been few studies focused only on grade 3 glioma. Postoperative radiotherapy in combination with chemotherapy has improved the prognosis of highgrade glioma, with the median OS reported as two years for AA and four years for AO [6], although the prognosis is highly variable depending on factors such as the extent of resection and molecular markers [79]. The prognosis in our study was comparable to that in previous studies.

In glioblastoma, it is thought that malignant cells migrate along the PE; however, the PTV margin is limited to an enhanced region plus $2 \mathrm{~cm}$ after $50 \mathrm{~Gy}$. That is, some part of the extended edema does not receive a full dose of irradiation. Thus, Liang et al. suggested that EPE was a significant factor for the prognosis of glioblastoma and concluded that it is better to irradiate PE up to $60 \mathrm{~Gy}$ as much as possible [2]. In grade 3 cases, the European Organisation for Research and Treatment of Cancer (EORTC) and Radiation Therapy Oncology Group (RTOG) trial 26053 suggested that the gross tumor volume (GTV) should be defined as the entire region of high signal intensity on T2-weighted MRI or FLAIR, plus the enhanced region on preoperative CT/MRI if available, or as the enhanced region on postoperative CT/MRI if preoperative imaging is not available, plus the tumor resection margin [10]. The CTV is then defined as a $1.5-2.0-\mathrm{cm}$ volumetric expansion of the GTV; the PTV adds $0.5-0.7 \mathrm{~cm}$, and a total dose of $59.4 \mathrm{~Gy}$ is given in 33 fractions.

Minniti et al. have suggested that larger irradiated volumes could be directly responsible for clinically relevant toxicities, and isotropic expansion of $15 \mathrm{~mm}$ from the GTV to the CTV is now generally accepted [11]. Before these recommendations, we had used the cone down technique for grade 3 gliomas, as well as for glioblastoma [3-5]. For the initial 46-50 Gy, we defined CTV-1 as the tumor bed or cavity and surrounding edema plus $1.5-\mathrm{cm}$ margins, with CTV-2 then defined as only the tumor bed or cavity plus a $1.5-\mathrm{cm}$ margin for the subsequent 10-14 Gy. Therefore, when PE was extended to $>2 \mathrm{~cm}$, some part of the PE was excluded from CTV-2. However, our results suggested that EPE was a significant factor for a poor prognosis for PFS, but not for OS, in grade 3 glioma. In a case with EPE $(>2 \mathrm{~cm})$, all PE was irradiated up to $50 \mathrm{~Gy}$, but part of the PE area was not irradiated after $50 \mathrm{~Gy}$ in this study. This may suggest that a tumor component was contained in the PE area and that $50 \mathrm{~Gy}$ is insufficient to control this component. The reason why OS did not decrease despite the higher recurrence rate is unclear. There may be more options for treatment after recurrence, compared to glioblastoma, and in clinical practice, we actively use retreatment methods such as surgery, reirradiation, and bevacizumab for a recurrent tumor.

To our knowledge, this is the first study of PE in grade 3 glioma, and more information is needed to determine whether the PE area should be irradiated up to $60 \mathrm{~Gy}$. However, our results indicate that this approach may be better, to the extent that it is possible. Contrast enhancement reflects areas of neoangiogenesis and occurs where the blood-brain barrier is disturbed in tumor areas. However, there are few reports on the correlation between contrast enhancement and prognosis in one grade [12-16]. Lote et al. conducted a large study investigating the significance of contrast enhancement within intracranial glioma, including 947 adult patients with glioma (low grade in 336, grade 3 in 104, and glioblastoma in 481). 
The findings suggested that tumor contrast enhancement was strongly associated with high-grade histology, but was an independent negative prognostic factor in multivariate analysis, despite numerous previous studies finding that enhancement is associated with high-grade glioma. Among grade 3 cases, $62 \%$ showed contrast enhancement, and these patients had significantly shorter survival than those with nonenhanced tumors. Our study confirms the finding that a contrast-enhanced tumor has a poor prognosis. Thus, it may be assumed that the pathological condition of a non-enhanced tumor is closer to that of a lowgrade tumor.

This study has many limitations, including its retrospective design, which prevented the evaluation of molecular factors. Of particular note, the significance of $1 \mathrm{p} / 19 \mathrm{q}$ codeletion [17-19] and mutation of isocitrate dehydrogenase 1 or 2 (IDH1-mt or IDH2-mt) [17,19-21] has recently been established with regard to the prediction of the prognosis of gliomas. Some recent reports indicate that $1 \mathrm{p} / 19 \mathrm{q}$ codeletion and MGMT are significantly associated with OS and PFS even in an analysis targeting only grade 3 gliomas [22-24].

\section{Conclusions}

Based on our findings, a preoperative contrast-enhanced tumor on MRI and a longer PE may also be significantly associated with OS or PFS of grade 3 glioma. However, there is no information on genetic aspects that are considered to significantly affect the OS and PFS of grade 3 glioma. Hence, further studies are required to gain insight into the topic, especially genetic information.

\section{Additional Information \\ Disclosures}

Human subjects: Consent was obtained or waived by all participants in this study. Tsukuba Clinical Research \& Development Organization issued approval H30-114. The Ethics and Steering Committees of Tsukuba approved this study and written informed consent was obtained from every patient prior to radiotherapy. The study was conducted in accordance with the Declaration of Helsinki, and the protocol was approved by the Institutional Review Board (Tsukuba Clinical Research \& Development Organization, H30114). Animal subjects: All authors have confirmed that this study did not involve animal subjects or tissue. Conflicts of interest: In compliance with the ICMJE uniform disclosure form, all authors declare the following: Payment/services info: All authors have declared that no financial support was received from any organization for the submitted work. Financial relationships: All authors have declared that they have no financial relationships at present or within the previous three years with any organizations that might have an interest in the submitted work. Other relationships: All authors have declared that there are no other relationships or activities that could appear to have influenced the submitted work.

\section{References}

1. White ML, Zhang Y, Kirby P, Ryken TC: Can tumor contrast enhancement be used as a criterion for differentiating tumor grades of oligodendrogliomas?. AJNR Am J Neuroradiol. 2005, 26:784-90.

2. Liang HT, Chen WY, Lai SF, et al.: The extent of edema and tumor synchronous invasion into the subventricular zone and corpus callosum classify outcomes and radiotherapy strategies of glioblastomas. Radiother Oncol. 2017, 125:248-57. 10.1016/j.radonc.2017.09.024

3. Mizumoto M, Yamamoto T, Ishikawa E, et al.: Proton beam therapy with concurrent chemotherapy for glioblastoma multiforme: comparison of nimustine hydrochloride and temozolomide. J Neurooncol. 2016, 130:165-70. 10.1007/s11060-016-2228-4

4. Mizumoto M, Tsuboi K, Igaki H, et al.: Phase I/II trial of hyperfractionated concomitant boost proton radiotherapy for supratentorial glioblastoma multiforme. Int J Radiat Oncol Biol Phys. 2010, 77:98-105. 10.1016/j.ijrobp.2009.04.054

5. Stupp R, Dietrich PY, Ostermann Kraljevic S, et al.: Promising survival for patients with newly diagnosed glioblastoma multiforme treated with concomitant radiation plus temozolomide followed by adjuvant temozolomide. J Clin Oncol. 2002, 20:1375-82. 10.1200/JCO.2002.20.5.1375

6. Tham CK, See SJ, Tan SH, et al.: Combined temozolomide and radiation as an initial treatment for anaplastic glioma. Asia Pac J Clin Oncol. 2013, 9:220-5. 10.1111/ajco.12038

7. Walker MD, Alexander E Jr, Hunt WE, et al.: Evaluation of BCNU and/or radiotherapy in the treatment of anaplastic gliomas. A cooperative clinical trial. J Neurosurg. 1978, 49:333-43. 10.3171/jns.1978.49.3.0333

8. Green SB, Byar DP, Walker MD, et al.: Comparisons of carmustine, procarbazine, and high-dose methylprednisolone as additions to surgery and radiotherapy for the treatment of malignant glioma. Cancer Treat Rep. 1983, 67:121-32.

9. Dinapoli RP, Brown LD, Arusell RM, et al.: Phase III comparative evaluation of PCNU and carmustine combined with radiation therapy for high-grade glioma. J Clin Oncol. 1993, 11:1316-21. 10.1200/ICO.1993.11.7.1316

10. van den Bent MJ, Baumert B, Erridge SC, et al.: Interim results from the CATNON trial (EORTC study 2605322054) of treatment with concurrent and adjuvant temozolomide for $1 \mathrm{p} / 19 \mathrm{q}$ non-co-deleted anaplastic glioma: a phase 3, randomised, open-label intergroup study. Lancet. 2017, 390:1645-53. 10.1016/S01406736(17)31442-3

11. Minniti G, Amelio D, Amichetti M, et al.: Patterns of failure and comparison of different target volume delineations in patients with glioblastoma treated with conformal radiotherapy plus concomitant and adjuvant temozolomide. Radiother Oncol. 2010, 97:377-81. 10.1016/j.radonc.2010.08.020

12. Lote K, Egeland T, Hager B, Skullerud K, Hirschberg H: Prognostic significance of CT contrast enhancement 
within histological subgroups of intracranial glioma. J Neurooncol. 1998, 40:161-70. 10.1023/a:1006106708606

13. Pallud J, Capelle L, Taillandier L, et al.: Prognostic significance of imaging contrast enhancement for WHO grade II gliomas. Neuro Oncol. 2009, 11:176-82. 10.1215/15228517-2008-066

14. Daumas-Duport C, Varlet P, Tucker ML, Beuvon F, Cervera P, Chodkiewicz JP: Oligodendrogliomas. Part I: patterns of growth, histological diagnosis, clinical and imaging correlations: a study of 153 cases. J Neurooncol. 1997, 34:37-59. 10.1023/a:1005707203596

15. Daumas-Duport C, Tucker ML, Kolles H, et al.: Oligodendrogliomas. Part II: a new grading system based on morphological and imaging criteria. J Neurooncol. 1997, 34:61-78. 10.1023/a:1005759220434

16. Daumas-Duport C, Koziak M, Miquel C, et al.: Reappraisal of the Sainte-Anne Hospital classification of oligodendrogliomas in view of retrospective studies (Article in French). Neurochirurgie. 2005, 51:247-53. 10.1016/s0028-3770(05)83485-X

17. Balañá C, Alonso M, Hernandez-Lain A, et al.: Correction to: SEOM clinical guidelines for anaplastic gliomas (2017). Clin Transl Oncol. 2018, 20:937. 10.1007/s12094-018-1904-6

18. Ramirez C, Bowman C, Maurage CA, Dubois F, Blond S, Porchet N, Escande F: Loss of 1p, 19q, and 10q heterozygosity prospectively predicts prognosis of oligodendroglial tumors--towards individualized tumor treatment?. Neuro Oncol. 2010, 12:490-9. 10.1093/neuonc/nop071

19. Ruff MW, Uhm J: Anaplastic glioma: treatment approaches in the era of molecular diagnostics . Curr Treat Options Oncol. 2018, 19:61. 10.1007/s11864-018-0579-0

20. Yan H, Parsons DW, Jin G, et al.: IDH1 and IDH2 mutations in gliomas . N Engl J Med. 2009, 360:765-73. 10.1056/NEJMoa0808710

21. Sanson M, Marie Y, Paris S, et al.: Isocitrate dehydrogenase 1 codon 132 mutation is an important prognostic biomarker in gliomas. J Clin Oncol. 2009, 27:4150-4. 10.1200/JCO.2009.21.9832

22. Cairncross G, Wang M, Shaw E, et al.: Phase III trial of chemoradiotherapy for anaplastic oligodendroglioma: long-term results of RTOG 9402. J Clin Oncol. 2013, 31:337-43. 10.1200/JCO.2012.43.2674

23. Wick W, Roth P, Hartmann C, et al.: Long-term analysis of the NOA-04 randomized phase III trial of sequential radiochemotherapy of anaplastic glioma with PCV or temozolomide. Neuro Oncol. 2016, 18:1529-37. 10.1093/neuonc/now133

24. Wahner HC, Träger M, Bender K, et al.: Predicting survival in anaplastic astrocytoma patients in a singlecenter cohort of 108 patients. Radiat Oncol. 2020, 15:282. 10.1186/s13014-020-01728-8 